\title{
The Meaning of Applied Creativity in the Culinary Industry
}

\author{
Pearl LIN PhD \\ School of Hotel and Tourism Management \\ The Hong Kong Polytechnic University
}

\section{Tom BAUM}

Strathclyde Business School

University of Strathclyde

This is a peer-reviewed, accepted author manuscript of the following journal article: Lin, P. M. C., \& Baum, T. (2016). The meaning of applied creativity in the culinary industry. International Journal of Hospitality and Tourism Administration, 17(4), 429-448. DOI: $10.1080 / 15256480.2016 .1226153$ 


\section{The Meaning of Applied Creativity in the Culinary Industry}

The purpose of this paper is to present a study which explores the origin of applied creativity in the culinary industry, in Taiwan. A total of 36 Chinese and Western cuisine chefs from five-star hotels and top restaurants were interviewed to provide the data from this study. The findings indicate that the role of applied creativity in the culinary industry has played a key role in culinary change and evolution in Taiwan. Culinary creativity has its own distinct characteristics, such as time limitations and market acceptance, which are acquired through building blocks of professional skills and experience. The study contributes to understanding the role of applied creativity in the culinary industry.

Keywords: culinary creativity, culinary industry, culinary market Subject classification codes: Creativity and Innovation

\section{Introduction}

Creativity is the route to competitive advantage and a key method to gain competitive advantage over rivals (Hospers, 2003). In today's world, creativity is applied extensively to enhance value in products and services, such as high technology products, business and financial services, media and cultural industries, and neoartisanal manufacturing (Scott, 2006). In the West, creativity is seen as an effective solution to compete with new and inexpensive economies in Asia and elsewhere. Creativity plays a central role in stimulating economic growth in cities, regions and advanced capitalist economies in general (Steam, de Jong and Marlet, 2008). It is considered as a policy option for stimulating a range of wider economic, cultural and social outcomes. Creative industries are defined "in terms of a class of economic choice theory in which the predominant fact is that, because of inherent novelty and uncertainty, decisions both to produce and to consume are determined by the choice of others in a social network" (Potts, Cunningham, Hartley and Ormerod, 2008:169). 
Steam et al., (2008) classify creative industries into three domains: arts; media and publishing; and creative business services, within which the subject of this paper, culinary creativity, could legitimately be located. According to Richards (2011), in some cases the definition of creative industries has been expanded to include tourism (Bagwell, 2009; Bonink and Hitters, 2001; Evans, 2009 cited in Richards, 2011) and this research is probably the first exploration of culinary creativity within this broad context. The impetus for creativity can be linked to the broader process of globalization, commodification, raising competitions between cities, industries and the development of new economies (Richards, 2011). The phenomenon of creative cities and industries demonstrates that social, economic and political development can provide the appropriate underlying framework conditions to promote creative cities, industries and nations. Similarly, these environmental factors provide a clear wider context for culinary creativity.

The growth of creative approaches to the tourism industry can also be associated with numerous strategies to create unique places, including the promotion of creative industries, cities, and classes. "Arguably these various strategies manifest themselves concretely through the absorption of creative production and consumption into specific creative clusters" (Richards, 2011:1245). Consequently, the culinary industry can be seen as a core component of services which focus on experiences and which include wider engagement through tourism, special events, culture and sport.. Creativity in services, generally, presents challenges because of the intangible nature of much service delivery. Therefore, it is contendable that all areas within services need to conceptualize and develop their own, contextualized approach to their understanding creativity in that no generic, pan-services approach can be applied. As the culinary industry plays a dynamic and core role in both tourism and retail, culinary creativity can serve as a part 
of a robust medium to assist in the conceptualisation of creativity and innovation in both the tourism and retail sectors. . The culinary industry depends on the fact that eating is one of our daily routines. Eating is both a personal and social act (Brown, Edwards, and Hartwell, 2010: 206). In human living, when we dine out and to choose a restaurant, food and service are the most common considerations in mind. With restaurants constantly coming to the market with new culinary creations, the culinary industry is a highly competitive environment (Ottenbacher and Harrington, 2007). Success in this industry, therefore, depends on chefs who can be considered as the most influential people in the restaurant business and who have to continuously develop their culinary creations in order to satisfy their customers and achieve profit targets. However, culinary creativity is difficult to gauge by easily identifiable tools and measures. Consequently, the aim of this paper is to explore the meaning of applied creativity in five star hotels and upscale restaurants in the Taiwanese culinary industry in order to contribute to the future development of culinary education. The main objectives are to define culinary creativity and the role of applied creativity in the culinary industry. To achieve these objectives, this paper begins by evaluating relevant literature in applied creativity in the culinary industry and follows this by exploring the nature of the culinary industry. A presentation of empirical findings follows. The research participants were drawn from on top level restaurants and five star hotel chefs working within both Chinese and Western cuisine in Taiwan in order to ensure a similar level of culinary background. Finally, comparisons between the perspectives of participants from the two cuisines are presented.

\section{The difference between creativity and innovation}

The concepts of creativity and innovation are frequently interchangeable in the literature (Martins and Terblanche, 2003), so it is necessary to address how these 
concepts inter-relate in the context of this study. Creativity is a starting point for innovation by individuals and teams (Amabile et al., 1996:1154). "All innovation begins with creative ideas. Successful implementation of new programs, new product introductions, or new services depends on a person or a team having a good idea and developing that idea beyond its initial state". Yeh (2004) notes that innovation refers to the successful implementation of creative ideas within an organization. A majority of definitions of innovation are related to the implementation of "ideas, processes, products or procedures, new to the relevant unit of adoption, designed to significantly benefit the individual, the group, organization or wider society" (West and Farr, 1990:9), a definition that leaves innovation not so far removed from many explanations of creativity.

Kuratko and Hodgetts (1989) facilitate our understanding of innovation by classifying it into three types: extension, duplication and synthesis. Extension is a new use or different application of an already existing product, service or process. Duplication is a replication of an existing concept. Synthesis is a combination of existing concepts and factors into a new formulation. These classifications are similar to some definitions of creativity and, indeed as will be seen, provide a useful starting point for an examination of aspects of culinary endeavour. However, McLean (2005: 228) points out that innovation operates more at group and organizational levels with a focus on "interrelationship, interactions and dynamics among actors, components of the organization and its environment". McLean continues by making a distinction in that, "creativity is a phenomenon that is initiated and exhibited at the individual level. The individualistic approach to distinguishing the two concepts focuses on variables such as personality (Feist, 1999), motivation (Collins and Amabile, 1999), and expertise (Weisberg, 1999). Consequently, this approach leads to an interpretation of creativity as 
"the ability to produce work that is both novel and appropriate" (Sternberg and Lubart, 1999:3) which is often linked to an individual's ideas, invention and breakthrough (McLean, 2005).

This collective individual distinction leads to an approach which is extended by Roberts (1988) who sees innovation as 'invention + exploitation'. Invention is aimed at creating new ideas and applying them. This means that creativity is the first stage of the innovation process, an interpretation similar to Amabile's (2004:1) insight that "no innovation is possible without the creative processes", which includes identifying problems and opportunities, gathering relevant information, generating new ideas and exploring the validity of those ideas. In addition, exploitation includes commercial development, application and transfer toward objectives, an important extension in the context of this study of culinary creativity. Consequently, "innovation is a process whereby new ideas are put into practice" (Rickards, 1985:10). While both concepts have significance, it can be concluded that the concept of creativity is more appropriate in this culinary research, which explores individual's perspective in seeking to understand the origin of creativity in the culinary industry.

\section{Defining culinary creativity}

It can be noted that there are numerous definitions of creativity from different perspectives. Taylor (1988: 118) presents six major groups of creativity definitions that highlight the main themes in definitions. Firstly, "Gestalt" or "Perception" creativity emphasises the recombination of ideas or the restructuring of a "Gestalt." Wertheimer (1945) says that creativity is the process of destroying one gestalt in favour of a better one. Secondly, "end product" or "innovation" is considered in number of definitions. Stein (1953) explains that creativity is that process which results in a novel work that is accepted as tenable or useful or satisfying by a group at some point in time. The third 
group is, "Aesthetic" or "Expressive" creativity, where the major emphasis is upon selfexpression. Fourth, is "Psychoanalytic" or "Dynamic" creativity which is defined in terms of interactional strength ratios of the id, ego and superego. Fifthly, "Solution Thinking" creativity places the emphasis upon the thinking process itself rather than upon the actual solution of the problem. Finally, "Veria" creativity refers to what Rand (1952) sees as addition to the existing stored knowledge of mankind. From these six groups, some definitions contain elements that fall into different groups. Thus, in order to define creativity, one must consider a range of factors, which include interactions, translations, rearrangements, evolutions and stimulations, as well as the creator's (person) own abilities and personality in order to produce a product and be accepted and satisfied by a group. In summary, De Dreu (2010) summarizes a range of researchers' perspectives to conclude that creativity is often identified with three dimensions, person, product and process.

The purpose of creativity in the culinary industry is to increase sales and profit and improve the quality and reputation of an organization, which outcomes are vital to the advancement of culinary professions (Horng \& Hu, 2009b). However, creativity research in the area of the culinary arts has been relatively limited. Conceivably, culinary performance or outcomes are not often considered as visual arts. Culinary creativity is frequently seen to be tangible and considered as a "skill-oriented discipline" (Horng \& Lee, 2009: 100) to satisfy basic human needs (Horng \& Hu, 2008). Chossat and Gergaud (2003, p. 130) note that culinary creativity is aimed at introducing radical changes in the traditional way of cooking, or experimenting with new combinations of foodstuffs like fish and meat in the same course. Classical or traditional cooking signals the reproduction by a chef of the French gourmet cuisine standards or canons for example, voliaille en vessie or boeuf bourguignon. 
Culinary creativity has, arguably, played a key role in the culinary revolution. "The culinary revolution of nouvelle cuisine, which reimaged the food industry in the 1970s, was underpinned by creativity. Specific work advocates new training methods for chefs to help in upgrading the profession" (Gillespie 1994, Horng and Lee 2006 cited in Robinson, 2001:36) As example of the culinary revolution, la nouvelle cuisine Française is Bocuse's version of la cuisine du moment, was influenced by mentor Chef Point. The secret and soul of nouvelle cuisine lay in the simple act of following Chef Point's insistence on cooking according to the day's market, cooking it at the last minute, individually for each client, and cooking it perfectly. Further, Point demonstrates his philosophy of cooking that the simplest dishes that are the hardest to master (Chelminski, 2005: 6). The nouvelle cuisine approach could be one style of culinary creativity and is still deeply influenced by considerations of how cuisine should be prepared, presented and appreciated.

Horng and $\mathrm{Hu}$ (2009: 376) summarize that in the French culinary tradition, creativity is the refinement of classical or traditional culinary art (Chossat and Gergaud, 2003), and top chefs do need to know the classical arts to refine them. This is a representation of culinary refinement rather than development from completely new which is similar to the argument put forward by Robinson and Beesley (2010:767) who note that "a chef 'creates' a meal: raw ingredients are skilfully selected, prepared, combined, transformed, cooked and presented to be enjoyed by the consumer. From this perspective, creativity need not always mean something new or 'novel' as has hitherto been the focus of discussion, but is aligned more with 'creation', and where creativity (new and novel combinations of ingredients, variety, aesthetics, and 'artistry') exists on a continuum". 
Frumkin (2005: 78) presents interview findings with well-known chefs in the USA and the UK where each chef defines and describes culinary creativity differently. Culinary creativity can be considered 'of the moment', 'as a product', 'experience' (your growing up, your travels, your observations and memory), 'a cycle of change' (transformation), 'a process like playing musical instrument' and 'psychology and flavour memory' (childhood memory and experiments). Some chefs even question whether culinary creativity will be a valid concept a decade hence, asking whether a new wave of culinary invention is truly creative at all, contending that many new dishes that are being praised as original are simply reinterpretations of classic preparations (Frumkin, 2005:78). Parseghian (2002) argues that truly creative cuisine depends on the ability to combine the knowledge of various cultures and experience of other cultures and travel in order to stimulate culinary creativity. Therefore, the creation of a new culinary product requires merging into the nature of its style of cuisine, which echoes notions of with creativity as synonymous with cookery. This has its origins in antiquity, as evidenced in the writing of Apicius (Vehling, 1977 cited in Robinson, 2001:36 ) . Each cuisine represents the cultural background and history which lies behind it.

\section{The role of creativity in the culinary industry}

The culinary industry is a competitive and intensive business and a distinguishing culinary vision can have a powerful appeal to potential customers. Frumkin (2005:75) quotes Tim Zagat (the president of the Zagat food guide) who states, "unrestrained creativity is not the answer to a chef's prayers. Ultimately, it is whether the dish tastes wonderful” (Frumkin, 2005:75). Culinary creativity takes various manifestations, whether as a creative product, creative process, or creative person. A culinary product is received and is evaluated by customers; chefs develop product through the culinary process and are evaluated by food cost; the culinarian is nurtured 
by experience and/or education.

Whether a chef can be considered as an artist who produces an art work that is worthy of appreciation by customers, or whether she/he should be considered as a craftsman who has the required skills to produce good food to satisfy the hunger of consumers is an important question. Perhaps she/he can also be considered a scientist? There is some evidence from other researchers (Hegaty and O'Mahony, 2001; Peterson and Birg, 1988; Horng and Hu, 2008; Robinson, 2011) which claims that culinary production and gastronomy are fine arts, and chefs should therefore be considered as artists. By contrast, Vikneswaran (2008) notes that most chefs do not only know how and why things work, but also require some knowledge of scientific phenomena, such as emulsion and vacuum-packing. Thus, science has been recognised and applied in the culinary field for many decades. Fine (1992:1271) notes cooks have a set of conflicting identities, being simultaneously artists, professionals, businessmen and manual labours (Fine, 1981 cited in Fine, 1992). In addition, professional cooking is situated amid demands for aesthetic choice, consistency, efficiency, autonomy and highly skilled technical work (Hall 1975:188-200 cited in Fine, 1992). Farmer, Tierney, and KungMcintyre (2003) highlight that, in Chinese culture, social force and culture have strong influences on creative identity and performance. The hospitality environment in Taiwan is an open-minded market. Customers are always looking for new trends and creative tastes. Therefore, local street food, fast food restaurants, and fine dining restaurants are all searching for creativity in food and service. Some culinary creations may have a shorter life cycle than others, or, indeed, no success at all. Applied creativity in Taiwan culinary industry still remains as a significant strategy. 
The hospitality industry involves commercial organizations that specialize in providing accommodation and /or, food, and or/drink, through a voluntary human exchange, which is contemporaneous in nature, and undertaken to enhance the mutual well-being of the parties concerned (Brotherton and Wood, 2000:143).

Food, atmosphere and service are identified by Campbell-Smith (1967) as the key elements in restaurants and could impact commercially on the provided meal (Jenser \& Hansen, 2007:604). Thus, a restaurant is a commercial place, and customer tastes are always taken into consideration by chefs. Client demands are the main difference between the contemporary practitioners of the fine arts and chefs. Chefs are artists who can at least bend to client demands, and insist their occupational standings (Fine, 1996). In addition, Peterson and Birg (1988: 67) discuss the occupation of a chef who is more like a "commercial artist" who is "less fully under control of the artist and more directly subject to the wishes of the consumers". Perhaps, these culinary commercial artists are like many painters and writers who can produce their works, which are not necessary creative in the purest sense but are popular and fashionable and meet market demand. These considerations also relate to an individual chef's personality in that a chef can be more adventurous in risk taking or non-risk taking to develop his/her creations to fit or create the market demand. Horng and Lee (2006:11) propose four distinct experiences of creative culinary artists: professional knowledge and skills; comprehensive understanding of cultures; life experience; and cultivation of an aesthetic sense. Some of these characteristics are similar to the character of creative artists. Horng and Lee state that "culinary creativity is a product of the interaction between the inherently or innately creative individual". From the artists' perspective, culinary creativity is the way to express a personal style, which places emphasis on uniform creation. Unlike artists and writers, chefs' work places emphasis on uniqueness and problem solving (Peterson and 
Birg, 1988). In addition, Horng and Lee (2006) state that creative chefs have the characteristics of being willing to take reasonable risks, and being achievement-oriented to develop their creations.

Fine (1996:229) states that cooking has had an ambivalent and often distant relationship to the world of art. All diners agree that the sensory characteristics of what is served matter deeply to the outcome. Cooks must negotiate the ways in which they are expected to take aesthetic concerns into account but simultaneously must do this with the recognition that they are industrial employees, and that their ultimate goal, if they wish to remain employed, must be to prepare food so as to be profitable and to satisfy both customer and managers. This is a delicate balance in that it involves questions of autonomy and control, craft and labour.

The environmental effects on creativity development have been increasingly considered through the study of various senses, notably the work environment and the educational environment. The work environment is defined as the social climate of an organization which may include physical environmental variables (Amabile, 1989). Furthermore, social and environmental factors appear to play a critical role in creative performance, where social-psychological factors have an important impact on the productivity and creativity of outstanding individuals (Amabile, 1996; Boden, 1994). In today's scientific society, it is widely accepted that genetic and environmental factors, working in dynamic consort, influence intelligence (Reuter, 2007). Notwithstanding an individual's talents, expertise and skills, the conditions of a social environment can significantly increase or decrease the level of creativity produce (Amabile, 1996).

It is clear that the culinary industry is commercial and making profit and satisfying customers are the major concerns. The role of applied creativity in the culinary industry plays a sensitive role which is to continuously develop new ideas for 
culinary products but also to maintain a balanced position in matching culinary fashion and market demand.

A majority of assessments focus on measuring products or persons as creative in a way which is similar in form to conventional intelligence tests. Moran (2009) points out that to measure creativity (TV Choice Productions.) one should consider the interaction of the three components: individual (person); field (press); and domain (process). However, Moran (2009) also notes that this is limited by the need for precise measurement. On the other hand, creativity within the food industry and its organizations cannot be measured by objective means. In a practical and commercial sense, the creative product is produced and decided by the organization in order for it to proceed and be accepted by customers. Therefore, the majority of creative products are accessed in a business transaction. Ottenbacher and Gnoth (2005: 208) discuss measuring hospitality innovation success, where new services and products are most frequently based on financial measures of performance, for instance, revenue or profitrelated-measures, such as sales volume or market share. Other indirect benefits include: improved image and enhanced customer loyalty and the ability to attract new customers. In the same way, the culinary industry is part of the hospitality industry, where culinary creativity can be measured in a similar way to hospitality innovation, so it depends on profit making, customers' feedback and organizational support. The nature of culinary creativity is based on the commercial environment with an aesthetic approach to create and satisfy customers within a limited amount of time (Peterson \& Birg, 1988).

Whether fast food or fine dining, the importance of applied creativity in the culinary industry is more likely to act as a key factor to success. An example is of McDonald's fast food restaurants introducing Kimchee Beef burgers during the World Cup in Korea in 2002 which brought great success to their operations. On the other 
hand, the recent development of molecular cuisine by Spanish chef Ferran Adrià has highly impacted on the evolution of world cuisine. According to Svejenova, Mazza and Planellas (2007), Adrià has the reputation as the Picasso and the Dali of haute cuisine, the world's best chefs and one of the its most influential citizens. However, Ottenbacher and Harrington (2009) state that quick-service restaurants seem to apply as much creativity but target an area wider than just the creation of the menu item which leads to this research focus on one segment in five star hotels and upscale restaurant in Taiwan.

In summary, it seems that the role of applied creativity in the culinary industry demonstrates complex purposes, as an artistic form of cuisine to satisfy customers' demand, organizational goals and reputations. Still, defining the role of applied culinary creativity is still insufficient. What is required is to further investigate the characteristics of culinary creativity and its implications for the culinary industry and education. Therefore, this research focuses on exploring the role of applied creativity and its meanings in the culinary industry.

\section{Methodology}

The purpose of the interview method is to elicit views and opinions from participants (Creswell, 2009). Open-ended questions were used to identify possible determinants in the origin of culinary creativity and help to generate insights into how chefs perceive their culinary creativity, and in this way, establish the meaning of culinary creativity. The advantages of this method are that it offers a context for understanding behaviour and attitudes in developing creativity. It also assists in understanding complicated behavioural variances differences between Western and Chinese cuisines' chefs in terms of their differences in training background, experience and personal characteristics. In-depth and semi-structured interviews were applied in qualitative research in order to conduct discussions not only to reveal and understand 
culinary creativity and how to develop it but also to place more emphasis on exploring why culinary creativity is important in the industry (Saunders, Lewis, \& Thornhill, 2003). Additionally, the interview method can support an understanding of the relationships between variables, such as those revealed from a descriptive study where this is directly observed. This allows the researcher control over the line of questions. The researcher started by contacting participants by the phone and email to confirm date, time and location. Each interview lasted between one and one and half an hours. The interviews were digitally recorded and transcribed.

\section{Expert respondents}

This research utilizes expert participants to meet the study objectives. With very focused and deliberate sampling of Western and Chinese cuisine chefs in Taiwan, this research seeks to explore the meaning of culinary creativity from experienced and professional chefs within academia and industry in order to explore their opinions in relation to culinary creativity. Experts were selected based on their professional experience and current related work in the culinary industry and academia. Predominantly, participants contribute their perspectives based on their culinary industry and academic experiences. Experienced industry and academic chefs were able to share their knowledge and perspectives in this specific topic. Thirty-six expert participants were deemed appropriate for this research. Participant coding starts with a cuisine type W (Western cuisine) or C (Chinese cuisine), and includes the number of each participant in each category. For example, $\mathrm{C} 1$ represents chef number 1 in Chinese cuisine and $\mathrm{W} 1$ represents chef number 1 in Western cuisine. 
The interview questions consisted of four main themes. Four questions were conducted in Chinese, transcribed and translated by the researcher.

What is the nature of culinary creativity in the hospitality industry?

Define culinary creativity.

What is the difference between culinary creativity to creativity in general?

What are the differences between western cuisine and Chinese cuisine chefs' perspective of culinary creativity and develop?

The strength of data collection by interview strategy is that it allows probing by the interviewer, offers in-depth information and is good for measuring attitudes. On the other hand, the weakness of an interview data collection strategy is that it is time consuming and costly method. Also, the "reactive and investigator effects may occur" (Teddlie \& Tashakkori, 2009:239).

The reason for collecting qualitative data initially is the absence of creativity research in the culinary industry. According to Horng and $\mathrm{Hu}$ (2008), creativity research in the culinary arts has been largely neglected, perhaps because chefs are not often seen as culinary artists in the same sense that painters, musicians, and poets are seen as visual, musical, and literary ones. Without sufficient reference to creativity research as a background, this research will not be able to testify or verify any existing culinary creativity theories, nor measure quantitatively a large number of chefs' personal characteristics, training background and cultural background. Moreover, each chef has his/her own individual characteristics, in term of his/her social and cultural background. Thus, this particular group, chefs, is a better fit for qualitative method, interview 
strategy in order to understand complex patterns of chef behaviour in terms of their perspectives of culinary creativity.

\section{Coding process}

36 interviews were audio-recorded and transcribed in order to organize and prepare the data for analysis. Each interview was conducted individually over $1.5 \mathrm{hrs}$. to 2 hrs. First, interview data were divided between industry chef and academic chef data. After reading through all data, this was coded by hand into three main themes: defining culinary creativity, training and education and the gap between industry and academia. From each main theme, the data were developed into sub-themes in order to gain clear views as to their interrelationships. Themes and sub-themes are identified from interpretation of the meaning of the data.

\section{Findings}

All participants noted the importance of creativity to culinary industry from fast food to upscale fine dining as key to success. Respondents emphasised that 5 star hotels and upscale culinary creativity involves a wider range of skills and techniques than creativity in general. Most participants stated that culinary creativity builds on the fundamentals and basic principles of cooking which include knife skills, food science and knowledge, sanitation and hygiene, cooking methods and history in order to develop ideas and turn these into creativity. However, one participant (W2) did not agree that creativity has to be built up from tradition. He argued that building up from tradition may restrain creativity development.

\section{Defining culinary creativity}

Some of the participants felt that culinary creativity is difficult to achieve. Most of the time, culinary creativity is more like combining different elements into a new dish, 
rather than starting from scratch.

A creative dish can be defined broadly and more specifically, one as the cuisine itself, and the other is the packaging. Firstly, it is difficult to achieve culinary creativity. Frequently, we are just combining existing elements into a dish. For example: if you start with $\mathrm{A}+\mathrm{B}+\mathrm{C}$, then you can withdraw $\mathrm{B}$ and add $\mathrm{D}$. "I think it's more like a combination" (W9). To summarize, most participants' reported that culinary creativity is based on the foundations of traditional cuisine by adding various elements in order to extend and culinary traditions and also satisfy customers.

\section{The difference between culinary creativity and more general creativity}

According to all participants, there are two main characteristics (Figure 1) which can be considered in a definition of the nature of culinary creativity: 'market' (time limitations and commercially driven), and 'person' (practical experience and professional skills). Most participants pointed out that comparing culinary creativity and creativity in general highlights both similarities and differences. However, all participants agreed that the ultimate aim of both culinary creativity and more general creativity is acceptance by customers or the public.

Figure 1 Characteristics of Culinary Creativity

\section{Market}

Market is a place where chefs can present their culinary creations. On the other hand, market reaction is the reality test for culinary creations. Participants agreed that the ultimate goal of culinary creativity is to be recognized by the current market.

"As a chef, I need to know my market demand. If in this city, everyone likes to eat spicy food and the flavour of creation is mild, this may not be accepted by 
customers. On the other hand, if the current trend is for healthy cooking and my creation is heavy in flavour this may limit its success. Therefore, the market is a very important element to a chef's creativity where a chef can develop creations according to location, to source and age of customers and to market demand" (W17).

\section{Time}

Time imposes a limitation on culinary creativity, which does not appear to affect other forms of creativity to the same extent. Some of the participants pointed to time limitations as a distinct characteristic in the culinary industry within which a culinary creation has to be accepted within that specific period of time in order to gain acceptance by the market. Participants stated that the success of culinary creation success is typically measured by making profits and giving customers satisfaction (W2). Feasibility was also reported as a concern by some participants. Culinary creation should be saleable without involving too much increase in cost, notably labour. Therefore, the market, time limitations and feasibility are crucial elements in culinary creativity.

Unlike other arts, like architecture or music, culinary creativity has a very short shelf life unlike for example, Michaelangelo's David sculpture which was created between 1501-1504, and will stand in the museum forever (W9).

"If your culinary creation is not accepted by the market within that period of time, then this can't be called creativity. A painter's creation may not be accepted by people when he is alive. However, people can still evaluate this painter's artwork after he/she is dead" (W17).

\section{Commercially Driven}

The participants agreed that culinary creativity is driven by commercial sense 
which means its purpose is to make a profit and gain customer satisfaction.

Furthermore, participants admit that applied creativity has to be practical in an industry kitchen. It will not be called creative, if the creation is not making a profit and satisfying customers (W12).

"We are combining our local produce, winery, and handmade paper art gallery into our creative signature dishes which is not only of benefit to our restaurant business but also our local business" (C13).

A creative person should understand market demand and consider cost control in order to plan a new creation. Too high a cost will not attract customers to try a new creation (W11). Depending on the brand of hotel, or restaurant and its theme, some creativity may be limited and constrained by organizational business strategies and direction. To some five star chain hotels, culinary creativity may not be the first priority in kitchen operations (C2). Most hotels have their annual plans and promotions which may not require each kitchen outlet to develop original creations $(\mathrm{C} 11, \mathrm{~W} 10)$. Some theme restaurants, culinary creativity is required to match operational themes in order to create suitable products to match the restaurant environment (C13). Some participants also stated that decisions to put creativity into the menu depends on the owner's taste (C12, C14). However, participants who were also restaurant owners demonstrate more flexibility and control over their creativity development. Participants agreed that culinary creativity has to be considered alongside many other factors, for example: location, customers' preference, theme, and culture.

"Working in a five star hotel chain, most creations are from our executive chef team and also their sister hotels food promotions. My job is to transform these creations and promotions into business ideas. My job does not really involve much culinary creativity" (W14). 
"Sometimes, I like to add some new elements into my dishes. However, my boss (CEO) will restrain some of my creations. He does not like over exaggerated creations. Some loyal customers would also object to my creations, if they prefer the original dishes" (C12).

To summarize, culinary creativity is based on considerations of a restaurant's theme, location, target market, and final profit objectives. It seems that higher management positions (such as CEO and owner) can influence creativity directions and decisions. Hence, creativity in the culinary industry is commercially driven unlike much general creativity.

\section{Person}

Participants agreed culinary creativity puts emphasis on techniques in which experience accumulation and professional skills, in their career development are vital. Experience accumulation and professional skills include culinary knowledge, management, and cooking techniques where chefs can excel in their learning and experiences and move into a higher level of career. Experience accumulation from the culinary industry is a major source of advancing culinary creativity.

W12 gave the example of cutting vegetables from 10 times to 1000 times accumulating the experience of how to cut efficiently and precisely. It is the same as preparing a dish. Therefore, this participant thinks that experience accumulation is a key to developing culinary creativity. This is echoed by W1 who noted, that developing culinary creativity is similar to how the Chinese learn how to undertake traditional Chinese painting. First of all, you need to learn how to imitate cookery, followed by continuous practice. When you cook it over 100 times, you can naturally experience the key elements of a dish. Therefore, good foundation skills can enhance your creativity development and reduce your practice time. Professional skills are the foundation of 
the culinary vocation. Without professional knowledge and skills, it is difficult to learn to cook professionally and properly. A dish can be prepared by one, two or the whole team of kitchen staff in a way that is similar to playing music (W15).

"A song can be sung as a solo, chorus and other ways to express the flavour of this song, which is similar to cooking. You can cook a traditional dish with various combinations; however, the outcome has to depend on your experience and skills so that you know what elements can be combined well and work together" (W1).

Applied creativity in the culinary industry in Taiwan appears to have distinct characteristics as represent in the interview comments. In summary, it can be argued that applied creativity in the culinary industry is under the influence of and driven by internal (person) and external (market) factors. A chef has to create a dish which is based on his/her professional skills and experience accumulation to present to the market within time limitations.

\section{Discussion}

The nature of the culinary industry demonstrates that culinary creativity has an important role in business strategy. Culinary creativity can be considered as a form of artistic expression by a chef within the constraints of certain conditions. A majority of the study participants considered themselves as culinary artists with some degree of food science knowledge underpinning their art. This outcome supports Preston and Birg (1988), Hegarty and O’Mahony (2001), and Horng and Hu (2006) who noted that chefs can be seen as culinary artists. All participants expressed various perspectives of how creativity is considered an important strategy in the culinary industry. To some extent, applied creativity in the culinary industry is a fashion (Horng and $\mathrm{Hu}, 2006$ ), which can lead and change people's taste buds (C9). In addition, C12 indicated that real culinary 
creation should be able to last for a long period of time (from generation to generation). He gave the example of some classic Chinese dishes, such as Kung Pao Chicken and Longjin Tea Shrimps. However, C2 noted that culinary creations happen at different levels and across various themes of restaurants. He stated that culinary creativity in hotels and upscale restaurants may not be as important as popular (mid-level) restaurants. This outcome contradicts Ottenbacher and Gnoth (2005) who hold that Michelin restaurant chefs strive for culinary innovation to achieve success. Mainly, hotels and upscale restaurants have demonstrated high quality and standard in culinary production. All participants agreed the final goal of culinary creativity is to satisfy customers and make a profit in order to survive in a very competitive industry, and this corresponds with the views of Ottenbacher and Gnoth (2007), and Horng and Lee (2009). In addition, Peterson and Birg (1988) propose that chefs are like 'commercial artists'. This research argues that within the time limitations and customer-orientation constraints, chefs can be considered to be contemporary commercial artists who have to meet current market demand and achieve profit goals for their organizations.

\section{Character of culinary creativity}

The findings of this study demonstrate that the characteristics of culinary creativity are constrained by market (market acceptance, time limitations) and person (practical experience and professional skills) factors. From the market perspective (market acceptance and time limitations), chefs have limited time to create culinary products which are required to meet market demand in a commercial sense. The market perspective (market acceptance and time limitations) is parallel to the notion of time as one of the critical factors that impact on market reaction according to Getz and Lubart (2009), and Peterson and Birg (1988). Moreover, participants noted that the market is not only the culinary market in general but also reflects regional/local market demand. 
Some participants noted that, depending on the type of cuisine and source of customers, chefs are required to understand market demand in order to present proper creations to the market. From the person perspective (practical experience and professional skills), to ignite culinary creativity, chefs are required to have experience and professional skills in order to spark their creativity and be appreciated by customers. The majority of Chinese cuisine participants emphasised the importance of practical experience to their creativity development. On the other hand, Western cuisine kitchens adopt standard operations procedures (SOP) by which the formula for recipes is given so that they can easily prepare the components of a dish (C9). For example, a Caesar salad can be simply prepared by a trainee or a line cook, whereas, a Chinese cuisine kitchen might have difficulties in building a SOP system. Essentially, Chinese cuisine tends to present one dish to share with a table of people (10-12 people). For example, to cook a whole fish, a chef has to consider the individual size of the fish in order to determine the deepfrying temperature and timing. This depends on the chef's experience (C9). On the other hand, Western cuisine presents a single portion per person, which can be prepared by a line cook with SOP (standard operation procedure) recipes. As a consequence, the accumulation of practical experience could contribute to a chefs' culinary creativity development. The expert panel agreed that the accumulation of both practical experience and professional skills are the basic elements of culinary creativity development. This outcome agrees, in part, with Horng and Lee (2009) that culinary creativity is a skill-oriented discipline. However, this research argues that practical experience appears as an important element in the development of culinary creativity.

\section{Defining culinary creativity}

From the literature, the only published definition of creativity in the culinary industry is that of Chossat and Gergaud (2003) who state that "in the French culinary 
tradition, creativity is the refinement of classical or traditional culinary art" (Horng and $\mathrm{Hu}, 2006: 376)$. Following this, Ottenbacher and Harrington (2007) discuss commercialization in the case of a Michelin-starred restaurant, where chefs focus on customer satisfaction and long-term reputation rather than food cost or profit margin.

Some aspects are similar to earlier literature. For instance, C2, and W2 defined culinary creativity as to destroy and create a better entity, similar to Werthimer (1954), while, some research participants saw culinary creativity as to create from fundamentals, (traditional and/or original) without missing the essence. Perhaps they noted culinary creativity as a type of rearrangement of traditional or classical dishes. This reflects the importance of culinary foundations. Similarly, Harmon (1955 cited in Taylor, 1988:118) illustrates this as "any process by which something new is produced an idea or an object, including a new form or arrangement of old elements". In addition, this outcome corresponds with the notion of an "addition to existing stored knowledge of mankind" proposed by Rand (1952).

Some participants demonstrated different views of culinary creativity. For example, $\mathrm{C} 8$ argued that culinary creativity is developed from stress, which a chef must be able to deal with in order to survive. This can be explained within the reality of the culinary industry as a competitive service industry. Chefs are obliged to develop a new creation constantly. Experts agreed that with a successful culinary creation, a chef can be the leader of that field of expertise. This outcome supports the notion of Stierand and Lynch (2008). For example, Chef Adrià (the restaurant owner of elBulli in Spain) advances culinary development by incorporating scientific aspects into a 'new cooking' (molecular cuisine) so that it became a top creative cuisine trend worldwide (Stierand and Lynch, 2008). More importantly, participants pointed out that culinary creation should be able to survive the challenge of time and last forever. To some of chefs, 
culinary creativity is a refinement and recombination process, which supports the definition by Chossat and Gergaud (2003). To a majority of chefs, culinary creativity is built upon the fundamentals, which are inspired by cultural background and traditions. However, W9 argued that to create from tradition may constrain creativity development. All chefs agreed that culinary creativity is developed from the foundations of skills and experience in order to present original and competitive products, satisfy customers and make a profit. To elaborate on previous literature definitions, this research argues that culinary creativity can be defined as based on the foundation of traditional cuisine with additional elements which extend and emerge from culinary traditions and satisfy customers.

\section{Conclusions}

This paper explores creativity in its applied services sector context by focusing on the forms it takes in the culinary industry. It is argued that culinary creativity has its own distinct characteristics which it plays an important role in culinary evolution and in education and training for work in this area. The findings of this research have implications which go beyond the specific culinary context and have meaning in related areas of what might be styled experiential services, such as those delivered by sommeliers, through special events and within areas of retail. Within all of these areas, an applied, time-constrained and commercialised interpretation of creativity, such as that explored in the culinary context in this paper, has resonance and relevance.

The findings of this study indicate that the role of applied creativity in the culinary industry has played a key role in the culinary revolution, which is considered as a leading trend to change customers' taste and dining experience. It has its own distinct characteristics, for example time limitations and market acceptance, which are acquired 
through building blocks of professional skills and experience. These distinct characteristics present a perspective on unique basic principles of creativity development in the culinary industry. To summarize participants' perspective of culinary creativity, this is based on the foundation of traditional cuisine by adding various elements in order to extend and "escape" from culinary traditions and to satisfy customers. The study contributes to an understanding of the role of applied creativity in the culinary industry from the perspective of Chinese and Western cuisine chefs in a Chinese cultural context. To extend the discussion of Peterson and Birg (1988), this study argues that, within the limitations of time and customer-orientation, chefs can be considered as contemporary commercial artists who have to present their creations to meet current market demand and achieve profitability in the organization in order to survive in the industry. In addition, the characteristics of culinary creativity are constrained by market acceptance, time limitations, professional skills (Horng and Lee, 2009) and practical experience. This study highlights that practical experience is considered as an essential element in the development of culinary creativity. In particular, without standard operating procedures in Chinese cuisine kitchens, practical experience appears to be rather more important to Chinese cuisine chefs than Western cuisine chefs. Therefore, by exploring the meaning of applied creativity, this qualitative findings show the importance of creativity in the culinary industry which it can assist in planning culinary training and education in the future.

This study was conducted in Taiwan with thirty-six participants who are Chinese and specialize in either Chinese cuisine or Western cuisine. The findings reflect the cultural influences of both cuisines. Future research areas can be extended to different cultures and countries or other comparable contexts using a diversity of methodological approaches. 


\section{References}

Amabile, T. M. (1996). Creativity in context. Colorado: Westview Press, Inc.

Amabile, T., Conti, R., Coon, H., Lazenby, J., \& Herron, M. (1996). Assessing the Work Environment for Creativity. Academy of Management Journal, 39(5), 1154-1185. Amabile, T. (2004). Innovation \& Creativity quotes. Retrieved March 19, 2012,from http://www.innovationtools.com/Quotes/Quotes.asp?page=5.

Brotherton, B. and Wood, R. C. (2000) Defining Hospitality and Hospitality Management. In: C. Lashley and A. Morrison (eds.), In Search of Hospitality - Theoretical Perspectives and Debates. Oxford: Butterworth Heinemann, 134156.

Brown, L., Edward, J., \& Hartwell, H. (2010). A taste of the unfamiliar: understanding the meanings attached to food by international postgraduate students in England. Appetite, 54(1), 202-207. doi:10.1016/j.appet.2009.11.001

Campbell-Smith, G. (1967). The Marketing of the Meal Experience. Guildford: Surrey University Press.

Chelminski, R. (2005). The Perfectionist: life and death in haute cuisine. New York: Penguin Group (USA) Inc.

Chossat, V., \& Gergaud, O. (2003). Expert opinion and gastronomy: The recipe for success. Journal of Cultural Economics, 27(2), 127-141.doi: 10.1023/A:1023432502059

Creswell, J. W. (2009). Research design : qualitative, quantitative, and mixed methods approaches (3rd ed.). Thousand Oaks: Sage Publications.

De Dreu, C. K. W. (2010). Human Creativity: Reflections on the Role of Culture Management and Organization Review (6), 437-446.

Farmer, S. M., Tierney, P., \& Kung-Mcintyre, K. (2003). Employee creativity in Taiwan: an application of role identity theory. Academy of Management Journal, 46 (5), 618-630

Feist, G. J. (1999). The Influence of Personality on Artistic and Scientific Creativity. In R. J. Sternberg (Ed.), Handbook of Creativity (pp. 273-296). Cambridge: Cambridge University Press. 
Fine, G. A. (1992). The Culture of Production: Aesthetic Choices and Constraints in Culinary Work. American Journal of Sociology, 97(5), 1268-1294. doi:10.1086/229902

Fine, G. A. (1996). Kitchens: the culture of restaurant work. Berkeley: University of California Press.

Frumkin, P. (2005). Chefs Seek New Inspiration for Culinary Magic. Nation's Restaurant News, 39.

Getz, I., \& Lubart, T. I. (2009). Creativity and economics: current perspectives. In T. Rickards, M. A. Runco \& S. Moger (Eds.), The Routledge Companion to Creativity (pp. 206-221). Oxon: Routledge Taylor \& Francis Group.

Hegarty, J. A., \& O'Mahony, G. B. (2001). Gastronomy: A phenomenon of cultural expressionism and an aesthetic for living. International Journal of Hospitality Management,20(1), 3-13.doi: 10.1016/S0278-4319(00)00028-1

Horng, J. S., \& Lee, Y. C. (2006). What Does It Take to Be a Creative Culinary Artist? Journal of Culinary Science \& Technology, 5(2/3), 5-22.

Horng, J. S., \& Hu, M. L. (2008). The Mystery in the Kitchen: Culinary Creativity. Creativity Research Journal, 20(2), 1-10.doi:10.1080/10400410802060166

Horng, J. S., \& Lee, Y. C. (2009). What environmental factors influence creative culinary studies? International Journal of Contemporary Hospitality Management, 21(1), 100-117.doi: 10.1108/09596110910930214

Hospers, G.-J. (2003). Creative Cities: Breeding Places in the Knowledge Economy. Knowledge, Technology, \& Policy, 16(3), 143-162.

Jenser, Ø., \& Hansen, K. V. (2007). Consumer Values Among Restaurant Customers. International Journal of Hospitality Management, 26,603622.doi:10.1016/j.ijhm.2006.05.004

Kuratko, D. F., and Hodgetts, R. M. (1989). Entrepreneurship: a Contemporary Approach. Chicago: The Dryden Press.

Martins, E. C., \& Terblanche, F. (2003). Building Organisational Culture that Stimulates Creativity and Innovation. European Journal of Innovation Management, 6(1), 64-74.

McLean, L. D. (2005). Organizational Culture's influence on Creativity and Innovation: A Review of the Literature and Implications for Human Resource 
Development. Advances in Developing Human Resources, 7(2), 226-246.

Moran, S. (2009). Creativity: a systems perspectives. In T. Rickards, M. A. Runco \& S. Moger (Eds.), The Routledge Companion to Creativity (pp. 292-301). Oxon: Routledge Taylor \& Francis Group.

Nair, V. (2008). Is culinary considered an Art or Science or both? Retrieved from http://drvnair.blogspot.com/2008/11/is-culinary-considered-art-or-science.html

Ottenbacher, M., \& Gnoth, J. (2005). How to Develop Successful Hospitality Innovation. Cornell University, 46(2), 205-222. doi:10.1177/0010880404271097

Ottenbacher, M., \& Harrington, R. (2007). The innovation development process of Michelin-starred chefs. International Journal of Contemporary Hospitality Management, 19(6), 444-460.doi:10.1108/09596110710775110

Ottenbacher, M., \& Harrington, R. (2009). The product innovation process of quickservice restaurant chains. International Journal of Contemporary Hospitality Management, 21 (5), 523-541. doi:10.1108/09596110910967782

Parseghian, P. (2002). Chefs color fall fare with creativity and value. Nation's Restaurant News, 36(39), 33, 169

Peterson, Y., \& Birg, L. D. (1988). Top Hat: the Chef as Creative Occupation. Free Inquiry in creative sociology, 16(1), 67-72.

Potts, J., Cunningham, S., Hartley, J., \& Ormerod, P. (2008). Social Network Markets: A New Definition of the Creative Industries. J Cult Econ, 32, 167-185.doi: 10.1007/s10824-008-9066-y

Rand, H. J. (1952). Creativity-Its Social economic and Political Significance. In F.Olsen (Ed). The Nature of Creative Thinking (pp. 12-15). New York: Industrial Research Institute Inc.

Richards, G. (2011). Creativity and Tourism, The State of the Art. Annals of Tourism Research, 38(4), 1225-1253.doi: 10.1016/j.annals.2011.07.008

Rickards, M. A. Runco \& S. Moger (Eds.), The Routledge Companion to Creativity (pp.206-221). Oxon: Routledge Taylor \& Francis Group.

Roberts, E. B. (1988). Managing Invention and Innovation. Research-Technology Management, Jan-Feb, 13. 
Robinson, R., \& Beesley, L. G. (2010). Linkages between creativity and intention to quit: An occupational study of chefs. Tourism Management, 31, 765776.doi:10.1016/j.tourman.2009.08.003

Robinson, R. N. S. (2011). Investigating Creativity as an Alternative Explicator of the Mobility of Chefs. Doctor of Philosophy, The University of Queensland, Australia.

Santich, B. (2004). The study of gastronomy and its relevance to hospitality education and training. International Journal of Hospitality Management, 23, 15-24.doi: $10.1016 / \mathrm{s} 0278-4319(03) 0069-0$

Saunders, M., Lewis, P., \& Thornhill, A. (2003). Research Methods for Business Students (3 ed.). England: Pearson Education Limited.

Scott, A. J. (2006). Creative Cities: Conceptual Issues and Policy Question. Journal of Urban Affairs, 28(1), 1-17.doi: 10.1111/j.0735-2166.2006.00256.x

Stam, E., Jong, J. P. J. d., \& Marlet, G. (2008). Creative Industries in the Netherlands:

Stein, M. I. (1953). Creativity and Culture. Journal of Psychology. 36, 311-322

Stierand, M., \& Lynch, P. (2008). The Art of Creating Culinary Innovations. Tourism and Hospitality Research, 8(4), 337-350.doi: 10.1057/thr.2008.28

Stenberg, R. J., \& Lubart, T. I. (1999). The Concept of Creativity: Prospects and Paradigms. In R. J. Sternberg (Ed.), Handbook of Creativity. Cambridge: Cambridge University Press.

Structure, Development, Innovativeness and Effects on Urban Growth. Geografiska Annaler: Series B, Human Geography, 90(2), 119-132.doi: 10.1111/j.14680467.2008.00282.x

Svejenova, S., Mazza, C., \& Planellas, M. (2007). Cooking up change in haute cuisine: Ferran Adrià as an institutional entrepreneur. Journal of Organizational Behaviour, 28 (5), 539-561.

Taylor, C. W. (1988). Various approaches to and definitions of creativity. In R. J. Sternberg (Ed.), The Nature of Creativity (pp. 99-121). New York: Cambridge University Press. 
Teddlie, C., \& Tashakkori, A. (2009). Foundations of Mixed Methods Research. Thousand Oaks: SAGE Publications, Inc.

Wertheimer, M. (1945). Productive Thinking. New York: Harper.

West, M. A. \& Farr, J. L. (1990). Innovation at work. In M.A. West \& J. L. Farr (Eds.), Innovation and Creativity at Work: 3-13. Chichester, UK: John Wiley \& Sons.

Yeh, Y. C. (2004). The interactive influences of three ecological systems on Rand Demplyees' technological creativity. Creativity Research Journal, 16(1), 11-25. 